Research

Open Access

\title{
Improved survival of children with sepsis and purpura: effects of age, gender, and era
}

\author{
Martine Maat ${ }^{1}$, Corinne MP Buysse ${ }^{2}$, Marieke Emonts ${ }^{1}$, Lodewijk Spanjaard ${ }^{3}$, Koen FM Joosten², \\ Ronald de Groot ${ }^{4}$ and Jan A Hazelzet ${ }^{2}$
}

\author{
1Department of Paediatrics, Division of Infectious Diseases and Immunology, Erasmus MC-Sophia Children's Hospital, University Medical Center, Dr. \\ Molewaterplein 60, 3015 GJ Rotterdam, The Netherlands \\ ${ }^{2}$ Department of Paediatrics, Division of Paediatric Intensive Care, Erasmus MC-Sophia Children's Hospital, University Medical Center, Dr. \\ Molewaterplein 60, 3015 GJ Rotterdam, The Netherlands \\ ${ }^{3}$ Netherlands Reference Laboratory for Bacterial Meningitis, Department of Medical Microbiology, Academic Medical Center Amsterdam, \\ Meibergdreef 15, 1100 DD Amsterdam, The Netherlands \\ ${ }^{4}$ Department of Paediatrics, University Medical Center St. Radboud, Geert Grooteplein 10, 6500 HB Nijmegen, The Netherlands \\ Corresponding author: Jan A Hazelzet, j.a.hazelzet@erasmusmc.nl
}

Received: 18 Jun 2007 Revisions requested: 18 Jul 2007 Published: 18 Oct 2007

Critical Care 2007, 11:R112 (doi:10.1186/cc6161)

This article is online at: http://ccforum.com/content/11/5/R112

(C) 2007 Maat et al; licensee BioMed Central Ltd.

This is an open access article distributed under the terms of the Creative Commons Attribution License (http://creativecommons.org/licenses/by/2.0), which permits unrestricted use, distribution, and reproduction in any medium, provided the original work is properly cited.

\begin{abstract}
Background To gain insight into factors that might affect results of future case-control studies, we performed an analysis of children with sepsis and purpura admitted to the paediatric intensive care unit (PICU) of Erasmus MC-Sophia Children's Hospital (Rotterdam, The Netherlands).
\end{abstract}

Methods Between 1988 and 2006, all 287 children consecutively admitted with sepsis and purpura were included in various sepsis studies. Data regarding age, gender, ethnicity, serogroup of Neisseria meningitidis, severity, therapy, and survival were collected prospectively. These data were pooled into one database and analyzed retrospectively.

Results The case fatality rate (CFR) from sepsis and purpura was $15.7 \%$. During the study period, survival improved significantly. Younger age was significantly associated with more severe disease and a higher CFR. Children under the median age of 3.0 years had an increased risk of case fatality (odds ratio 4.3, 95\% confidence interval 2.1 to $9.2 ; p<0.001$ ). Gender was not associated with CFR. However, males did have higher Paediatric Risk of Mortality scores, fewer PICU-free days, and more presence of shock. The course of sepsis and purpura was not related to ethnic origin. A causative organism was isolated in $84.3 \%$ of cases. $N$. meningitidis was the major organism (97.5\%). Although N. meningitidis serogroup B was observed more often in younger children, serogroups were not associated with severity or survival. During the study period, the use of inotropic agents and corticosteroids changed substantially (less dopamine and more dobutamine, norepinephrine, and corticosteroids).

Conclusion Age and gender are determinants of severity of paediatric sepsis and purpura. Survival rates have improved during the last two decades.

\section{Introduction}

Sepsis and purpura in children is a clinically distinct disease entity caused by high concentrations of microbes and their products. Since the introduction of a vaccine against Haemophilus influenzae type $b$, more than $90 \%$ of the cases of sepsis and purpura in the Western world have been caused by Neisseria meningitidis [1-3]. The resulting disease entity is referred to as meningococcal sepsis.
Meningococcal sepsis in children develops when the initial host response to the infection becomes inappropriately amplified and dysregulated. Clinically, the onset is often insidious. After the development of the first petechiae, the patient rapidly deteriorates and may subsequently develop shock, disseminated intravascular coagulation (DIC), and ultimately organ failure. The severity of these symptoms requires immediate therapy $[4,5]$. Despite recent advances in therapy, the case

$\overline{\mathrm{CFR}}=$ case fatality rate; $\mathrm{Cl}=$ confidence interval; $\mathrm{CRP}=\mathrm{C}$-reactive protein; $\mathrm{DIC}=$ disseminated intravascular coagulation; $\mathrm{PDR}=$ predicted death rate; $\mathrm{PICU}=$ paediatric intensive care unit; $\mathrm{PRISM}=$ Paediatric Risk of Mortality; $r_{\mathrm{s}}=$ Spearman correlation coefficient. 
fatality rate (CFR) remains high and ranges from $4 \%$ to $40 \%$ $[1,6-8]$. The incidence of disease is highest among young children (0 to 4 years old) and adolescents [1-3]. In The Netherlands, meningococcal sepsis occurs in 4.5 per 100,000 inhabitants (2001). Due to the sudden increase in the incidence of meningococcal disease in 2001 , a national vaccination campaign against serogroup $C$ meningococci (2002) was implemented among children from 1 to 18 years of age $[9,10]$.

In recent years, many studies have focused on the elucidation of the pathogenesis of sepsis. However, much about the epidemiology of sepsis in children is still unknown. In this paper, we seek to describe the epidemiology of sepsis and purpura in children referred to the paediatric intensive care unit (PICU) of Erasmus MC-Sophia Children's Hospital in Rotterdam, The Netherlands. The aim of this study was to analyze the variation in severity and survival of children with respect to age, gender, ethnicity, and serogroup of $N$. meningitidis.

\section{Materials and methods}

The study was conducted in accordance with the Declaration of Helsinki. Permission for the study was obtained from the medical ethics committee of Erasmus MC.

\section{Participants}

All children admitted with sepsis and purpura (and/or petechiae) to the PICU of the Erasmus MC-Sophia Children's Hospital since 1988 were included. A vast majority of the children were previously included in Rotterdam-based sepsis studies [11-16]. Data regarding the remaining children with sepsis and purpura were derived from PICU admission records. Informed consent was obtained from parents or legal guardians of all children who were included in this study. Children were considered to have sepsis when they presented with tachycardia, tachypnea, and a body temperature of less than $36^{\circ} \mathrm{C}$ or greater than $38.5^{\circ} \mathrm{C}$ (rectal) [17]. Prospective data on all children were collected at various time points in the course of the disease. Both laboratory parameters and disease severity scoring systems, like Paediatric Risk of Mortality (PRISM) score and predicted death rate (PDR) based on the Rotterdam score, were selected as markers of severity of disease [18-20]. Additionally, presence of DIC and presence of shock were recorded as markers of severity $[17,19,21]$. The number of PICU-free days was determined on day 28 after admission using the date of admission and the date of discharge. A non-survivor had 0 PICU-free days. All laboratory parameters, obtained at baseline from an arterial blood sample, were collected within 4 hours after admission to the PICU.

Ethnicity was determined by checking patient information, and if it was not specified, first and last names were checked and ethnicity was determined by means of the combined name method [22]. Ethnicity was categorized into Dutch Caucasian, Turkish, Moroccan, Hindustani, African descent, and other. Serogrouping of $N$. meningitidis isolates was performed the Netherlands Reference Laboratory for Bacterial Meningitis Amsterdam using immunodiffusion with polyclonal antisera [23].

Figure 1

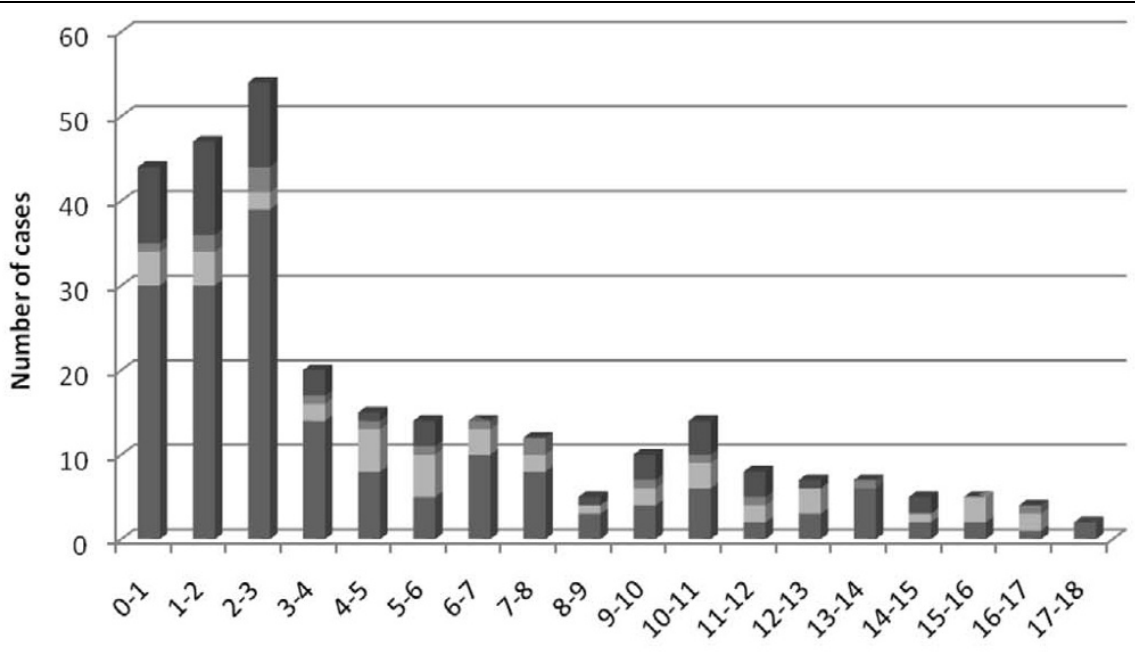

Age at admission (years)

$\square$ N. meningitidis serogroup $B \backsim N$. meningitidis serogroup $C \backsim N$. meningitdis n.f.d. $\square$ Other

Distribution of age at admission in children with sepsis and purpura. The children are subdivided according to causative organism. N. meningitidis, Neisseria meningitidis. Not further defined (n.f.d.). 
Table 1

\begin{tabular}{|c|c|c|}
\hline & Survivorsa & Non-survivorsa \\
\hline \multirow[t]{2}{*}{ Total number of children (\%) } & 242 & 45 \\
\hline & $(84.3)$ & $(15.7)$ \\
\hline Male-to-female ratio & 1.1 & 1.7 \\
\hline \multirow[t]{2}{*}{ Number of children with DIC (\%) } & $174^{\mathrm{b}}$ & $32^{b}$ \\
\hline & $(75)$ & $(97)$ \\
\hline \multicolumn{3}{|l|}{ Neisseria meningitidis serogroup } \\
\hline $\mathrm{B}(\%)$ & $147(74.2)$ & $28(73.7)$ \\
\hline $\mathrm{C}(\%)$ & $37(18.7)$ & $7(18.4)$ \\
\hline \multirow[t]{2}{*}{ PRISM score } & $14^{c}$ & $23^{c}$ \\
\hline & (1 to 37 ) & (8 to 44 ) \\
\hline \multirow[t]{2}{*}{ Predicted death rate (\%)d } & $3.1^{\mathrm{c}}$ & $87.4^{c}$ \\
\hline & (0 to 100$)$ & (1.1 to 100.0$)$ \\
\hline \multirow[t]{2}{*}{ Base excess (mmol/L) } & $-7 c$ & $-13^{c}$ \\
\hline & $(-23$ to 4.4$)$ & $(-28$ to 0.6$)$ \\
\hline Lactate $(\mathrm{mmol} / \mathrm{L})$ & $3.7^{\mathrm{c}}$ & $6.6^{c}$ \\
\hline Geometric mean, $95 \% \mathrm{Cl}$ & 3.4 to 4.3 & 5.8 to 7.4 \\
\hline \multirow[t]{2}{*}{ C-reactive protein (mg/L) } & $106^{c}$ & $53^{c}$ \\
\hline & (10 to 334$)$ & (6 to 226$)$ \\
\hline \multirow[t]{2}{*}{ Fibrinogen ( $g / L)$} & $2.8^{c}$ & $0.9^{c}$ \\
\hline & (0.3 to 6.8$)$ & $(0.2$ to 5.4$)$ \\
\hline \multirow[t]{2}{*}{ Platelet count $\left(\times 10^{3} / \mu \mathrm{L}\right)$} & $126^{c}$ & $47^{c}$ \\
\hline & (15 to 475 ) & (13 to 202$)$ \\
\hline Leukocytes $\left(\times 10^{3} / \mu \mathrm{L}\right)$ & $10.6^{c}$ & $4.7^{c}$ \\
\hline Geometric mean, $95 \% \mathrm{Cl}$ & 9.5 to 11.9 & 3.7 to 6.0 \\
\hline Glucose (mmol/L) & $6.3^{c}$ & $4.3^{c}$ \\
\hline Geometric mean, $95 \% \mathrm{Cl}$ & 5.9 to 6.8 & 3.6 to 5.3 \\
\hline
\end{tabular}

aResults represent median (min-max) unless stated otherwise. ${ }^{b} p<$ $0.01 .{ }^{c} p<0.001$. dPredicted death rate was based on the Rotterdam score. Cl, confidence interval; DIC, disseminated intravascular coagulation; PRISM, Paediatric Risk of Mortality.

\section{Statistical analyses}

Retrospectively, severity and survival of children with sepsis and purpura with respect to age, gender, causative organism, and ethnicity were analyzed by means of SPSS 11.01 (SPSS Inc., Chicago, IL, USA) Clinical and laboratory parameters were included in the analysis only if they were determined in at least $90 \%$ of all children.

Mann-Whitney $U$ test, Student $t$ test, chi-square test, and Spearman correlation $\left(r_{s}\right)$ were used when appropriate. When necessary, variables were log-transformed to obtain an

\section{Figure 2}

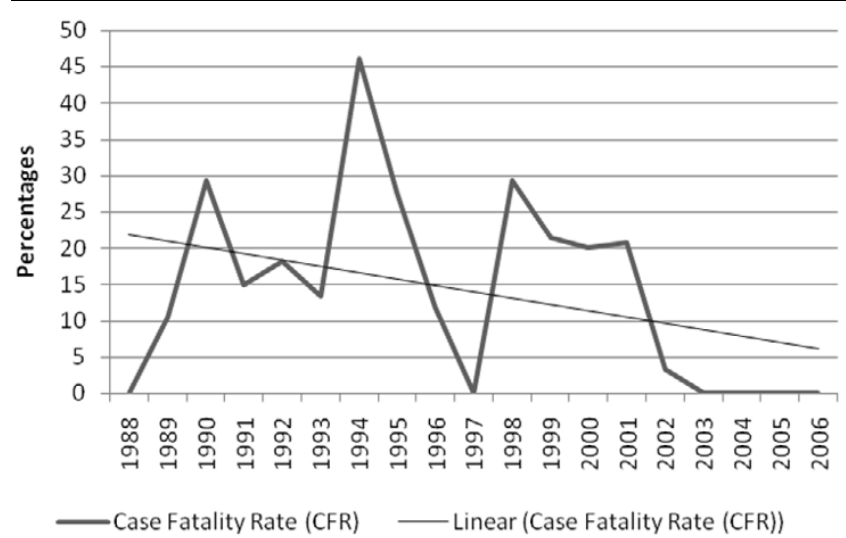

Case fatality rate (CFR) and CFR trend line during the study period.

approximately normal distribution. For these variables, geometric mean values and their 95\% confidence intervals (Cls) are depicted in the text and tables. $P$ values of less than or equal to 0.05 were considered statistically significant.

\section{Results}

Between August 1988 and June 2006, 287 children with sepsis and purpura were admitted to the PICU of the Erasmus MC-Sophia Children's Hospital. The overall CFR was $15.7 \%$ (45 children died). The median age at admission was 3.0 years (range 0.1 to 17.9 years) (Figure 1). Of the 287 children, 155 (54\%) were male and 132 (46\%) were female. The male-tofemale ratio was 1.2. The majority of the children were Dutch Caucasians (73.8\%). Laboratory parameters present at baseline in more than $90 \%$ of the children were base excess, lactate, C-reactive protein (CRP), fibrinogen, platelet count, leukocytes, and glucose.

\section{Survival}

Severity of illness was significantly less in survivors when compared with non-survivors, both in disease severity scoring systems and laboratory parameters (Table 1). Survival was significantly correlated with year of admission ( $p \leq 0.05, r_{s}$ 0.128 ), indicating that survival has improved significantly during the study period (Figure 2). Gender did not differ between survivors and non-survivors $(p=0.15)$. The vast majority of fatal cases died of refractory septic shock (75.6\%).

\section{Age}

Age was significantly correlated with PRISM score $(p<0.001$, $\left.r_{\mathrm{s}}-0.317\right)$, PDR $\left(p<0.001, \mathrm{r}_{\mathrm{s}}-0.321\right)$, presence of DIC $(p<$ $\left.0.001, r_{s}-0.245\right)$, base excess $\left(p<0.001, r_{s} 0.313\right)$, CRP $(p$ $\left.<0.05, r_{s} 0.161\right)$, fibrinogen $\left(p<0.001, r_{s} 0.301\right)$, leukocyte count $\left(p<0.001, r_{s} 0.284\right)$, thrombocyte count $\left(p<0.01, r_{s}\right.$ $0.184)$, and glucose levels $\left(p<0.001, r_{s} 0.296\right)$. This indicates that younger children had higher PRISM scores, higher PDR, more presence of DIC, lower base excess, lower CRP, 


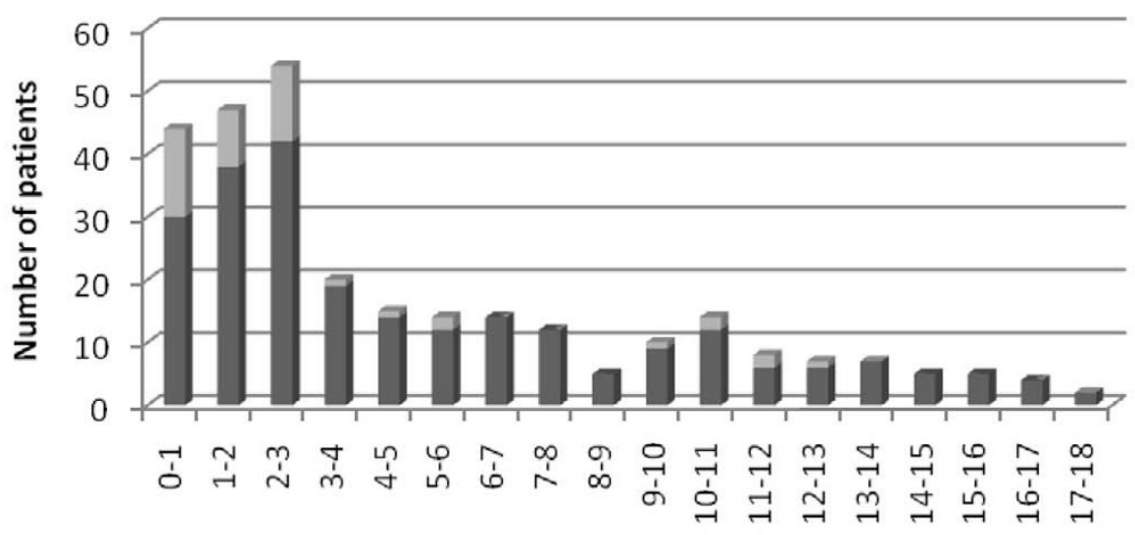

Age (years)

- Survivors Non-survivors

Distribution of age at admission among survivors and non-survivors of sepsis and purpura.

lower fibrinogen, lower leukocyte count, lower thrombocyte count, and lower glucose levels on admission. The median age of children was 3.0 years (range 0.1 to 17.9 years). Children 3.0 years old or younger had a higher CFR (odds ratio 4.3, $95 \% \mathrm{Cl} 2.1$ to $9.2 ; p<0.001$ ) (Figure 3).

\section{Gender}

The median age did not differ significantly between males (2.8 years) and females (3.5 years) $(p=0.16)$. Male patients had significantly fewer PICU-free days $(p=0.04)$ and higher PRISM scores $(p=0.02)$ than females. Shock was slightly more common in males than in females (89\% versus $80 \% ; p$ $=0.04)$. CFR and other markers of severity of disease did not differ between males and females. Because males had higher PRISM scores but no increased CFR, we analyzed the different variables determining the PRISM score. Of these variables, only a trend for lower glucose levels in males compared with females was observed $(p=0.06)$.

\section{Ethnicity}

The majority of the children were Dutch Caucasians $(n=211$, $73.5 \%)$. Of the remaining 76 children, 12 were Turkish $(4.2 \%)$, 16 were Moroccan (5.6\%), 3 were Hindustani (1.1\%), 7 were of African descent (2.5\%), 7 were designated other (2.5\%), and in 31 children ethnicity could not be determined (10.8\%). No differences with respect to severity of disease or case fatality were found between the different ethnic groups.

\section{Causative organism}

A causative organism could be determined in 242 children (84.3\%), with $N$. meningitidis being the major causative organism ( $n=236,97.5 \%$ ) (Figure 4). Of these 236, 175
(74.2\%) were $N$. meningitidis serogroup B, 44 (18.6\%) were serogroup $\mathrm{C}$, and in 17 (7.2\%) the serogroup was not determined (Table 2). Streptococcus pneumoniae was the causative organism in 3 children, Staphylococcus aureus in 1, and $H$. influenzae in 2 . Of the remaining 45 children, 43 had clinical features of meningococcal sepsis [3].

For logistic reasons, the causative organism could not be determined in 2 children. No differences with respect to survival, disease severity scoring systems, and presence of shock were observed between $N$. meningitidis serogroups $B$ and $C$. However, the median age of children with sepsis and purpura due to serogroup $B$ was lower than that of the serogroup $C$ infected children ( 2.8 and 6.0 years, respectively; $p<0.001$ ) (Table 3 ). The distribution of serogroup, serotype, and serosubtype of $N$. meningitidis in the positive cultures is depicted in Table 2.

\section{Meningococcal $\mathbf{C}$ vaccination campaign and therapy}

In 2001 and 2002, a sudden increase was noted in the incidence of meningococcal infection in The Netherlands. This was caused mainly by serogroup $C N$. meningitidis. The implementation of the meningococcal $\mathrm{C}$ vaccination campaign in July 2002 resulted in a sharp decline in the number of cases caused by serogroup C (Figure 4). Since 2003, there has not been a case of sepsis and purpura due to $N$. meningitidis serogroup $C$ in our hospital. Parallel to this, the incidence of serogroup $B$ has declined and is returning to the incidence level of before 1989. Before the national meningococcal C vaccination, 248 children in our study population were admitted with sepsis and purpura; since the vaccination campaign, 39 children have been admitted. 
Table 2

\begin{tabular}{|c|c|c|c|c|}
\hline Serogroup & Serotype & Serosubtype & Number & Percentage \\
\hline \multirow[t]{18}{*}{ B } & 1 & $\mathrm{P} 1.4$ & 4 & 1.8 \\
\hline & & $\mathrm{P} 1.16$ & 4 & 1.8 \\
\hline & & NT & 3 & 1.4 \\
\hline & & Other & 1 & 0.5 \\
\hline & $2 \mathrm{~A}$ & & 3 & 1.4 \\
\hline & 4 & $\mathrm{P} 1.4$ & 57 & 26 \\
\hline & & P1.6 & 3 & 1.4 \\
\hline & & $\mathrm{P} 1.7$ & 3 & 1.4 \\
\hline & & P1.9 & 4 & 1.8 \\
\hline & & $\mathrm{P} 1.10$ & 4 & 1.8 \\
\hline & & $\mathrm{P} 1.15$ & 5 & 2.3 \\
\hline & & NT & 28 & 12.8 \\
\hline & & Other & 13 & 5.9 \\
\hline & NT & $\mathrm{P} 1.1$ & 6 & 2.7 \\
\hline & & $\mathrm{P} 1.4$ & 8 & 3.7 \\
\hline & & NT & 8 & 3.7 \\
\hline & & Other & 4 & 1.8 \\
\hline & Other & & 17 & 7.8 \\
\hline \multirow[t]{9}{*}{ C } & $2 \mathrm{~A}$ & $\mathrm{P} 1.2$ & 12 & 5.5 \\
\hline & & $\mathrm{P} 1.5$ & 9 & 4.1 \\
\hline & & $\mathrm{P} 1.7$ & 1 & 0.5 \\
\hline & & NT & 7 & 3.2 \\
\hline & $2 B$ & $\mathrm{P} 1.1$ & 1 & 0.5 \\
\hline & & $\mathrm{P} 1.2$ & 7 & 3.2 \\
\hline & 4 & $\mathrm{P} 1.4$ & 3 & 1.4 \\
\hline & NT & & 2 & 0.9 \\
\hline & Other & & 2 & 0.9 \\
\hline
\end{tabular}

NT, non-typable.

Remarkably, since the implementation of meningococcal C vaccination, no deaths have occurred in children with sepsis and purpura admitted to our PICU. The median age of the children did not differ significantly before and after vaccination (3.2 and 2.5 years, respectively; $p=0.23$ ) (Table 4). Glucose levels were significantly lower in the patient group before the vaccination campaign compared with the patient group after $(p<0.05)$. Children admitted before the vaccination campaign had significantly fewer PICU-free days and more presence of DIC (both $p<0.05$ ). The PRISM score was not significantly different between patient groups before and after the meningococcal C vaccination campaign. In addition, since 2002, treatment of children with meningococcal sepsis at our PICU has changed due to the implementation of international guidelines [8]. After the vaccination campaign, more children were treated with corticosteroids (18 [9.3\%] before versus 15 [42.9\%] after; $p<0.001)$ and more children were mechanically ventilated (128 [51.8\%] before versus 28 [71.8\%] after; $p<0.05)$ (Table 3). In addition, year of admission was significantly correlated with the use of dobutamine $\left(p<0.001, r_{s}\right.$ $0.262)$, dopamine $\left(p<0.001, r_{s}-0.218\right)$, norepinephrine $(p<$ $\left.0.001, r_{\mathrm{s}} 0.329\right)$, and corticosteroids $\left(p<0.001, r_{\mathrm{s}} 0.245\right)$ but not with the use of epinephrine. This indicates that during the study period the use of dobutamine, norepinephrine, and cor- 


\section{Figure 4}

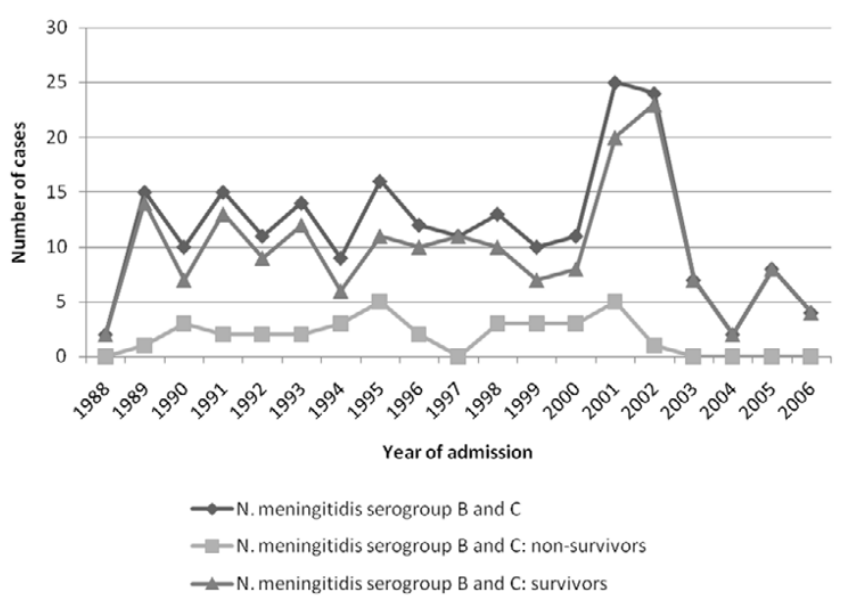

Number of children with sepsis and purpura due to Neisseria meningitidis per year (since 1988), admitted to the paediatric intensive care unit of Erasmus MC-Sophia Children's Hospital (Rotterdam, The Netherlands).

ticosteroids significantly increased in the treatment of sepsis and purpura whereas the use of dopamine significantly decreased (Figure 5).

\section{Discussion}

In this monocenter cohort study of 287 children between the ages of 0 and 18 years with sepsis and purpura, we found that younger children had more severe disease and an increased risk of case fatality. The CFR of sepsis and purpura has improved in recent years despite comparable disease severity on admission. Male patients had higher PRISM scores and fewer PICU-free days. However, the CFR did not differ between males and females. Ethnicity did not influence disease severity and survival. The serogroups of $N$. meningitidis were not related to severity or survival.

Children with sepsis and purpura admitted to the PICU of the Erasmus MC-Sophia Children's Hospital account for approximately $25 \%$ of all paediatric sepsis cases in The Netherlands and therefore may provide a representative sample of cases in The Netherlands (National PICU registry, unpublished data). In addition, Rotterdam covers an area in The Netherlands (that is, the southwest of The Netherlands) in which meningococcal disease used to occur frequently.

In this large cohort of paediatric sepsis and purpura, low age was significantly associated with increased severity of disease, higher incidence of DIC, and increased CFR. Half of the children in our population were younger than 3 years of age. A comparison with the literature showed that incidence rates indeed decline after infancy and then increase again slightly during adolescence $[1,9,24]$. The increased CFR and the more severe disease in younger children may result from the still-developing immune, coagulation, and stress response systems in young children and therefore from the relative inability of young children to induce an effective immune response to a high load of micro-organisms such as $N$. meningitidis $[13,19]$.

The CFR due to sepsis and purpura was $15.7 \%$ over the past two decades. This is in accordance with other large studies reporting CFRs of $10.4 \%$ to $20 \%$ [7,24-26]. It must be noted that Jensen and colleagues [7] and Sharip and colleagues [24] studied meningococcal disease, not specifically paediatric sepsis and purpura.

N. meningitidis was the causative organism of sepsis and purpura in the vast majority of cases. Martin and colleagues [27] also found that Gram-negative bacteria were the predominant causative organisms of sepsis in the US between 1979 and 1987. In our study, the incidence of disease due to serogroup $B$ was much higher than that due to serogroup C. Serogroup B N. meningitidis was seen more often in younger children compared with serogroup C. No differences with respect to severity of illness scores and CFR were observed between serogroups $B$ and $C$. Erickson and De Wals [28] suggested a more severe course of serogroup $\mathrm{C}$ infections, indicated by increased mortality due to serogroup $C(14 \%)$ compared with serogroup B (7\%). Spanjaard and colleagues [29] found a CFR in meningococcal sepsis caused by serogroup $B$ of $8.1 \%$ compared with $7.1 \%$ in serogroup C. However, Erickson and De Wals [28] studied both meningitis and sepsis in all cultureproven cases of $N$. meningitidis, and Spanjaard and colleagues [29] studied all culture-proven cases including adults in The Netherlands, whereas we studied paediatric cases of sepsis and purpura.

Since the implementation of the meningococcal $\mathrm{C}$ vaccination in July 2002, there has not been a fatal case of sepsis and purpura in our PICU. Because severity of disease before and after the implementation did not differ between the two groups, the increased survival may have resulted from improved treatment strategies [8]. International treatment guidelines were implemented at that time, health care workers received additional training, and public awareness increased, resulting in a decreased patient delay. Furthermore, we observed a change in the choice of inotropic agents used since 2002. It must be noted that the number of children included since 2002 is low. However, these observations do warrant further research in a prospective study.

Gender was not associated with CFR from sepsis and purpura although males did have significantly more severe disease, based on the PRISM score and fewer PICU-free days, compared with females. Bindl and colleagues [30] found a maleto-female ratio of 1.7 in sepsis patients ages 1 week to 8 years with severe sepsis and septic shock, whereas we observed a male-to-female ratio of 1.2. However, in those cases caused by $N$. meningitidis, which is the major causative organism in 


\begin{tabular}{|c|c|c|}
\hline & \multicolumn{2}{|c|}{ N. meningitidis ${ }^{\mathrm{a}}$} \\
\hline & Serogroup B & Serogroup C \\
\hline Total number of children & 175 & 44 \\
\hline \multirow[t]{2}{*}{ Age in years } & $2.8^{b}$ & $6.0^{b}$ \\
\hline & (0.1 to 17.9$)$ & (0.1 to 16.5$)$ \\
\hline \multirow[t]{2}{*}{ PRISM score } & 16 & 14 \\
\hline & (1 to 37 ) & (1 to 35$)$ \\
\hline \multirow[t]{2}{*}{ Predicted death rate $(\%)^{c}$} & 8.9 & 4.9 \\
\hline & (0 to 100$)$ & (0 to 100$)$ \\
\hline \multirow[t]{2}{*}{ Number of children with DIC (\%) } & 128 & 32 \\
\hline & (81) & (74) \\
\hline \multirow[t]{2}{*}{ Number of PICU-free days } & 24 & 25 \\
\hline & (0 to 28 ) & (0 to 27$)$ \\
\hline \multirow[t]{2}{*}{ Base excess (mmol/L) } & -8 & -8.0 \\
\hline & $(-21$ to 4.4$)$ & $(-28$ to 3$)$ \\
\hline Lactate $(\mathrm{mmol} / \mathrm{L})$ & 4.2 & 3.5 \\
\hline Geometric mean, $95 \% \mathrm{Cl}$ & 3.8 to 4.6 & 2.9 to 4.2 \\
\hline \multirow[t]{2}{*}{ C-reactive protein (mg/L) } & $82^{d}$ & $128^{d}$ \\
\hline & (6 to 287 ) & (20 to 326$)$ \\
\hline \multirow[t]{2}{*}{ Fibrinogen (g/L) } & 2.4 & 2.8 \\
\hline & $(0.2$ to 6.8$)$ & (0.3 to 6.6$)$ \\
\hline \multirow[t]{2}{*}{ Platelet count $\left(\times 10^{3} / \mu \mathrm{L}\right)$} & 110 & 113 \\
\hline & (15 to 475$)$ & (13 to 336$)$ \\
\hline Leukocytes $\left(\times 10^{3} / \mu \mathrm{L}\right)$ & $8.8^{e}$ & $12.2^{\mathrm{e}}$ \\
\hline Geometric mean, 95\% Cl & 7.6 to 10.1 & 9.9 to 15.0 \\
\hline Glucose (mmol/L) & 5.9 & 6.2 \\
\hline Geometric mean, $95 \% \mathrm{Cl}$ & 5.4 to 6.5 & 5.5 to 6.9 \\
\hline
\end{tabular}

aResults represent median (min-max) unless stated otherwise. $b_{p}<0.001$. cPredicted death rate was based on the Rotterdam score. ${ }^{d} p<0.01$. e $p$ $<0.05$. Cl, confidence interval; DIC, disseminated intravascular coagulation; PICU, paediatric intensive care unit; PRISM, Paediatric Risk of Mortality.

our study, males and females were represented equally among non-survivors. Watson and colleagues [26] and Martin and colleagues [27] also found a predisposition for male gender in sepsis, but they did not specify the male-to-female ratio in sepsis caused by N. meningitidis.

Due to the small number of children in the different ethnic groups, we may not have been able to detect differences between the different ethnic groups with respect to severity or case fatality of sepsis and purpura. In addition, during the 18year study period, the dynamics of the Dutch population (especially in Rotterdam) underwent changes, which may not be reflected in this study. Rosenstein and colleagues [1] pro- posed a predisposition for sepsis in children of African descent. Sharip and colleagues [24] found an age-adjusted increased risk of case fatality in individuals of African descent compared with Caucasians and other ethnic groups.

A possible limitation of our study may be that the serotypes of $N$. meningitidis were not determined in all children with meningococcal sepsis. Due to the rapidly progressive nature of this disease, it is possible that we did not include a number of the most severe cases because of case fatality before admission or referral to the Erasmus MC-Sophia Children's Hospital. On the other hand, the fact that only children with sepsis and purpura admitted to the PICU were included may have resulted in 
Table 4

Comparison of disease characteristics between children with sepsis and purpura before and after the national meningococcal $\mathrm{C}$ vaccination campaign (July 2002)

\begin{tabular}{|c|c|c|}
\hline & Before meningococcal $\mathrm{C}$ vaccination ${ }^{\mathrm{a}}$ & After meningococcal $\mathrm{C}$ vaccination ${ }^{\mathrm{a}}$ \\
\hline \multirow[t]{2}{*}{ Total number of children (\%) } & 248 & 39 \\
\hline & $(86.4)$ & $(13.6)$ \\
\hline \multirow[t]{2}{*}{ Case fatality (\%) } & $45^{b}$ & $0^{\mathrm{b}}$ \\
\hline & $(18.1)$ & $(0)$ \\
\hline \multirow[t]{2}{*}{ Age in years } & 3.2 & 2.5 \\
\hline & (0.1 to 17.9$)$ & (0.3 to 13.1$)$ \\
\hline \multirow[t]{2}{*}{ Number of children with DIC (\%) } & $186^{c}$ & $20^{c}$ \\
\hline & $(79.5)$ & $(62.5)$ \\
\hline \multirow[t]{2}{*}{ Number of PICU-free days } & $24^{c}$ & $25^{c}$ \\
\hline & (0 to 28$)$ & (0 to 27$)$ \\
\hline \multirow[t]{2}{*}{ PRISM score } & 15 & 20 \\
\hline & (1 to 44$)$ & (2 to 37 ) \\
\hline \multirow[t]{2}{*}{ Predicted death rate $(\%)^{d}$} & 5.6 & 8.1 \\
\hline & (0 to 100$)$ & (0 to 100$)$ \\
\hline \multirow[t]{2}{*}{ Base excess (mmol/L) } & -7.7 & -8 \\
\hline & $(-28$ to 4.4$)$ & $(-18$ to -2$)$ \\
\hline Lactate (mmol/L) & 4.1 & 4.0 \\
\hline Geometric mean, $95 \% \mathrm{Cl}$ & 3.8 to 4.4 & 3.3 to 4.8 \\
\hline \multirow[t]{2}{*}{ C-reactive protein (mg/L) } & 93 & 84 \\
\hline & (6 to 326$)$ & (25 to 334$)$ \\
\hline \multirow[t]{2}{*}{ Fibrinogen ( $g / L)$} & 2.5 & 3.2 \\
\hline & (0.2 to 6.8$)$ & (0.3 to 6.4$)$ \\
\hline \multirow[t]{2}{*}{ Platelet count $\left(\times 10^{3} / \mu \mathrm{L}\right)$} & 110 & 135 \\
\hline & (13 to 475$)$ & (25 to 227 ) \\
\hline Leukocytes $\left(\times 10^{3} / \mu \mathrm{L}\right)$ & 8.9 & 12.1 \\
\hline Geometric mean, $95 \% \mathrm{Cl}$ & 7.9 to 10.0 & 9.4 to 15.6 \\
\hline Glucose (mmol/L) & $5.7^{c}$ & $7.2^{\mathrm{c}}$ \\
\hline Geometric mean, $95 \% \mathrm{Cl}$ & 5.3 to 6.2 & 6.2 to 8.2 \\
\hline
\end{tabular}

aResults represent median (min-max) unless stated otherwise. ${ }^{b} p<0.01 .{ }^{c} p<0.05$. dPredicted death rate was based on the Rotterdam score. $\mathrm{Cl}$, confidence interval; DIC, disseminated intravascular coagulation; PICU, paediatric intensive care unit; PRISM, Paediatric Risk of Mortality.

a skewed representation of all children with sepsis and purpura (that is, children with relatively mild disease admitted to a general ward).

\section{Conclusion}

The CFR in this study was $15.7 \%$. Age was the most important predictor of severity and case fatality of sepsis and purpura. Male gender was associated with higher PRISM scores and fewer PICU-free days, but no differences in CFR were seen. $N$. meningitidis was the causative organism in the vast majority of cases. No differences between $N$. meningitidis serogroups $\mathrm{B}$ and $\mathrm{C}$ with respect to disease severity scores and case fatality were observed. Ethnicity was not associated with the course of sepsis and purpura.

In future studies investigating effects on severity and survival of sepsis and purpura, age and gender should be taken into account. The possible effect of the change in choice of inotropic agents warrants further investigation. Also, other possible differences between male and female patients with 
Figure 5

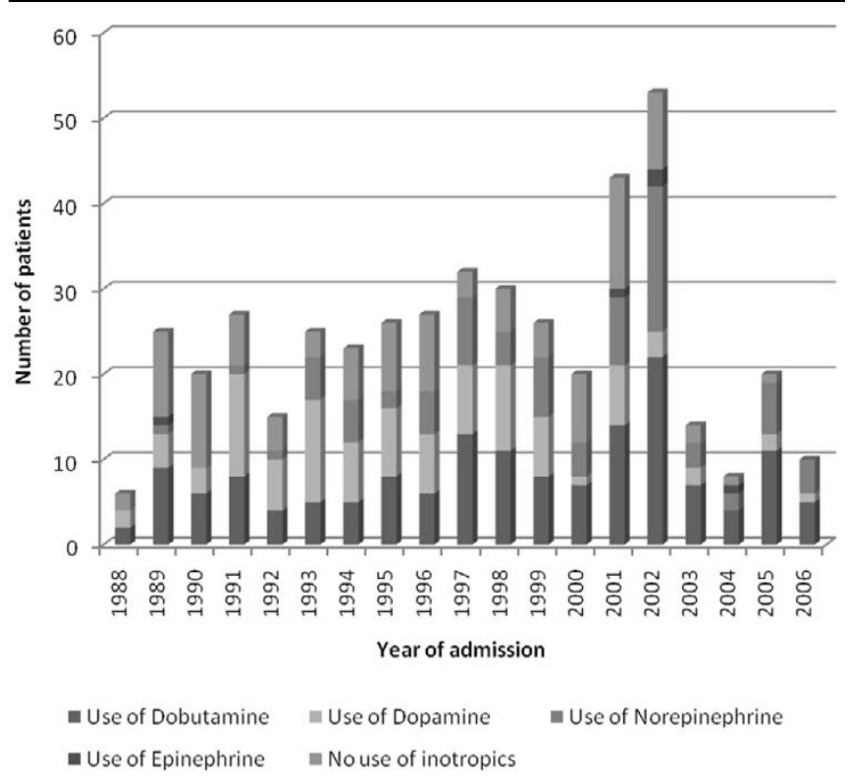

Use of inotropic agents during the study period 1988 to 2006 . Some patients received more than one inotropic agent. Therefore, the number of patients in this figure exceeds the number of patients in this study ( $N$ $=287$ ).

sepsis should be investigated. With the changing demography in The Netherlands (especially in the Rotterdam area), differences between ethnic groups require further examination.

\section{Key messages}

- Mortality of children with sepsis and purpura improved substantially from 1988 to 2006 . A possible explanation is an improvement in supportive treatment.

- Younger children (below 3 years of age) have a more severe disease state and a higher risk of case fatality than older children.

- Male patients have a more severe disease according to disease severity scoring systems, but this has not led to increased mortality in this group of 287 children.

- The major causative organism of sepsis and purpura in children is Neisseria meningitidis. Since the introduction of the vaccination in 2002, N. meningitidis serogroup $\mathrm{C}$ has completely vanished as a causative organism.

- Serogroup of N. meningitidis and ethnicity were not associated with the course of disease in children with sepsis and purpura.

\section{Competing interests}

The authors declare that they have no competing interests.

\section{Authors' contributions}

MM participated in creating the database, performed the statistical analysis, and wrote the manuscript. CMPB assisted in creating the database, interpretation of the results, and the writing of the manuscript. ME assisted in creating the database, the statistical analysis, interpretation of the results, and the writing of the manuscript. LS was responsible for N. meningitidis serogrouping and serotyping and critically read the manuscript. KFMJ critically read the manuscript and assisted in interpretation of the results. RdG assisted in the writing of the manuscript and was responsible for the studies in which the patients were included. JAH was also responsible for the studies in which the patients were included, initiated this study, and assisted in the statistical analysis, interpretation of the results, and the writing of the manuscript. All authors read and approved the final manuscript.

\section{Acknowledgements}

There was no financial support for this study.

\section{References}

1. Rosenstein NE, Perkins BA, Stephens DS, Popovic T, Hughes JM: Meningococcal disease. N Engl J Med 2001, 344:1378-1388.

2. Cohen J: The immunopathogenesis of sepsis. Nature 2002, 420:885-891.

3. Hazelzet JA: Diagnosing meningococcemia as a cause of sepsis. Pediatr Crit Care Med 2005, 6(3 Suppl):S50-54.

4. Vermont $\mathrm{CL}$, de Groot R, Hazelzet JA: Bench-to-bedside review: genetic influences on meningococcal disease. Crit Care 2002, 6:60-65.

5. Guarner J, Greer PW, Whitney A, Shieh WJ, Fischer M, White EH, Carlone GM, Stephens DS, Popovic T, Zaki SR: Pathogenesis and diagnosis of human meningococcal disease using immunohistochemical and PCR assays. Am J Clin Pathol 2004, 122:754-764.

6. Emonts M, Hazelzet JA, de Groot R, Hermans PW: Host genetic determinants of Neisseria meningitidis infections. Lancet Infect Dis 2003, 3:565-577.

7. Jensen ES, Schonheyder HC, Lind I, Berthelsen L, Norgard B Sorensen HT: Neisseria meningitidis phenotypic markers and septicaemia, disease progress and case-fatality rate of meningococcal disease: a 20-year population-based historical follow-up study in a Danish county. J Med Microbiol 2003, 52(Pt 2):173-179.

8. Booy R, Habibi P, Nadel S, de Munter C, Britto J, Morrison A, Levin $M$, Meningococcal Research Group: Reduction in case fatality rate from meningococcal disease associated with improved healthcare delivery. Arch Dis Child 2001, 85:386-390.

9. Netherlands Reference Lab for Bacterial Meningitis. Bacterial Meningitis in The Netherlands 2001. Amsterdam, The Netherlands: University of Amsterdam; 2002.

10. Netherlands Reference Lab for Bacterial Meningitis. Bacterial Meningitis in The Netherlands 2002. Amsterdam, The Netherlands: University of Amsterdam; 2003:11.

11. Vermont $C L$, den Brinker $M$, Kâkeci $N$, de Kleijn ED, de Rijke YB, Joosten KF, de Groot R, Hazelzet JA: Serum lipids and disease severity in children with severe meningococcal sepsis. Crit Care Med 2005, 33:1610-1615.

12. den Brinker $M$, Joosten $\mathrm{KF}$, Liem $\mathrm{O}$, de Jong $\mathrm{FH}$, Hop WC, Hazelzet JA, van Dijk M, Hokken-Koelega AC: Adrenal insufficiency in meningococcal sepsis: bioavailable cortisol levels and impact of interleukin- 6 levels and intubation with etomidate on adrenal function and mortality. $J$ Clin Endocrinol Metab 2005, 90:5110-5117.

13. de Groof F, Joosten KF, Janssen JA, de Kleijn ED, Hazelzet JA, Hop WC, Uitterlinden $P$, van Doorn J, Hokken-Koelega AC: Acute stress response in children with meningococcal sepsis: important differences in the growth hormone/insulin-like 
growth factor I axis between nonsurvivors and survivors. $J$ Clin Endocrinol Metab 2002, 87:3118-3124.

14. de Kleijn ED, de Groot R, Hack CE, Mulder PG, Engl W, Moritz B, Joosten KF, Hazelzet JA: Activation of protein $C$ following infusion of protein $\mathrm{C}$ concentrate in children with severe meningococcal sepsis and purpura fulminans: a randomized, doubleblinded, placebo-controlled, dose-finding study. Crit Care Med 2003, 31:1839-1847.

15. Derkx B, Wittes J, McCloskey R: Randomized, placebo-controlled trial of HA-1A, a human monoclonal antibody to endotoxin, in children with meningococcal septic shock. European Pediatric Meningococcal Septic Shock Trial Study Group. Clin Infect Dis 1999, 28:770-777.

16. Van der Kaay DC, De Kleijn ED, De Rijke YB, Hop WC, De Groot $R$, Hazelzet JA: Procalcitonin as a prognostic marker in meningococcal disease. Intensive Care Med 2002, 28:1606-1612.

17. Goldstein B, Giroir B, Randolph A: International pediatric sepsis consensus conference: definitions for sepsis and organ dysfunction in pediatrics. Pediatr Crit Care Med 2005, 6:2-8

18. Zuppa AF, Nadkarni V, Davis L, Adamson PC, Helfaer MA, Elliott MR, Abrams J, Durbin D: The effect of a thyroid hormone infusion on vasopressor support in critically ill children with cessation of neurologic function. Crit Care Med 2004, 32:2318-2322.

19. Kornelisse RF, Hazelzet JA, Hop WC, Spanjaard L, Suur MH, van der Voort E, de Groot R: Meningococcal septic shock in children: clinical and laboratory features, outcome, and development of a prognostic score. Clin Infect Dis 1997, 25:640-646.

20. Pollack MM, Ruttimann UE, Getson PR: Pediatric risk of mortality (PRISM) score. Crit Care Med 1988, 16:1110-1116.

21. Taylor FB Jr, Toh CH, Hoots WK, Wada H, Levi M: Towards definition, clinical and laboratory criteria, and a scoring system for disseminated intravascular coagulation. Thromb Haemost 2001, 86:1327-1330.

22. Bouwhuis $\mathrm{CB}, \mathrm{Moll}$ HA: Determination of ethnicity in children in The Netherlands: two methods compared. Eur J Epidemiol 2003, 18:385-388.

23. van der Ende A, Schuurman IG, Hopman CT, Fijen CA, Dankert J: Comparison of commercial diagnostic tests for identification of serogroup antigens of Neisseria meningitidis. J Clin Microbiol 1995, 33:3326-3327.

24. Sharip A, Sorvillo F, Redelings MD, Mascola L, Wise M, Nguyen DM: Population-based analysis of meningococcal disease mortality in the United States: 1990-2002. Pediatr Infect Dis J 2006, 25:191-194.

25. van Deuren $M$, Brandtzaeg $P$, van der Meer JW: Update on meningococcal disease with emphasis on pathogenesis and clinical management. Clin Microbiol Rev 2000, 13:144-166.

26. Watson RS, Carcillo JA, Linde-Zwirble WT, Clermont G, Lidicker $J$, Angus DC: The epidemiology of severe sepsis in children in the United States. Am J Respir Crit Care Med 2003, 167:695-701.

27. Martin GS, Mannino DM, Eaton S, Moss M: The epidemiology of sepsis in the United States from 1979 through 2000. N Engl J Med 2003, 348:1546-1554

28. Erickson L, De Wals P: Complications and sequelae of meningococcal disease in Quebec, Canada, 1990-1994. Clin Infect Dis 1998, 26:1159-1164.

29. Spanjaard L, Bol P, de Marie S, Zanen HC: Association of meningococcal serogroups with the course of disease in the Netherlands, 1959-83. Bull World Health Organ 1987, 65:861-868.

30. Bindl L, Buderus S, Dahlem P, Demirakca S, Goldner M, Huth R, Kohl M, Krause M, Kühl P, Lasch P, ESPNIC ARDS Database Group, et al: Gender-based differences in children with sepsis and ARDS: the ESPNIC ARDS Database Group. Intensive Care Med 2003, 29:1770-1773. 